\title{
ELECCIONES GENERALES EN IRLANDA
}

El día 27 de enero de 1982, el Dail irlandés (Cámara de Representantes) rechazaba las propuestas de presupuestos económicos presentadas por el primer ministro Garret Fitzgerald (Fianna Fail, moderado). Como consecuencia de este rechazo, Fitzgerald presentó su dimisión y el presidente Hillary la aceptó, ordenando la disolución del Parlamento (Oireachtas) y convocando al electorado irlandés a elecciones generales. La fecha de estas elecciones fue fijada para el día 18 de febrero de 1982.

El gobierno saliente era el resultado de la coalición formada por el Fine Gael (centro) y el Labour Party (laborista) tras las anteriores elecciones generales, convocadas también de forma anticipada ${ }^{1}$.

Como resultado de las elecciones del 18 de febrero, los asientos del Dail irlandés quedaron distribuidos de la siguiente manera en comparación con el Dail resultante de las anteriores elecciones (11-VI-81):

\section{Cuadro 1}

\section{EL DAIL TRAS LAS ELECCIONES}

\begin{tabular}{|c|c|c|c|}
\hline & Escaños 1982 & Escaños 1981 & Variación \\
\hline Fianna Fail (moderado) ... ... & 81 & 78 & +3 \\
\hline Fine Gael (centrista) $\ldots \ldots \ldots$ & 63 & 65 & -2 \\
\hline Labour Party $\ldots \ldots \ldots \ldots$ & 15 & 15 & - \\
\hline $\begin{array}{llllllll} & \text { S. F.W. } \\
* & \ldots & \ldots & \ldots & \ldots & \ldots\end{array}$ & 3 & 1 & +2 \\
\hline $\begin{array}{llllllll}\text { Otros } & \ldots & \ldots & \ldots & \ldots & \ldots & \ldots & \ldots\end{array}$ & 4 & 7 & -3 \\
\hline
\end{tabular}

* S.F.-W.P.: Sinn Fein-The Workers' Party.

FueNTE: Embajada de la República de Irlanda.

${ }^{1}$ Cfr. Fernando Ollero Butler, «Las elecciones al Dail irlandés», en Revista de Derecho Politico, núm. 11. 
Cuadro 2

DISTRIBUCION DE LOS ESCAÑOS POR CIRCUNSCRIPCIONES ELECTORALES

\begin{tabular}{|c|c|c|c|c|c|}
\hline CIRCUNSCRIPCION & $\begin{array}{l}\text { Número } \\
\text { de } \\
\text { escaños }\end{array}$ & F. F. & F. G. & L. P. & Otros \\
\hline Carlow-Kilkenny ... ... ..... & 5 & 2 & 2 & 1 & \\
\hline Cavan-Monaghan .......... & 5 & $3(2) *$ & 2 & & \\
\hline 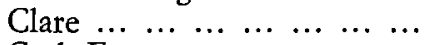 & 4 & 3 & 1 & & \\
\hline Cork East $\ldots \ldots \ldots \ldots \ldots \ldots$ & 4 & 1 & 2 & & $1 * *$ \\
\hline Cork North-Central ... . . . .. & 5 & 2 & 2 & 1 & \\
\hline Cork North-West $\ldots \ldots \ldots$ & 3 & 1 & 2 & & \\
\hline Cork South-Central ... ... ... & 5 & 2 & 2 & 1 & \\
\hline Cork South-West $\ldots$... & 3 & 1 & 2 & & \\
\hline Donegal North-East ... . . . ... & 3 & 1 & 1 & & 1 \\
\hline Donegal South-West ......... & 3 & 2 & 1 & & \\
\hline Dublin Central $\ldots \ldots \ldots$ & 5 & 2 & $1(2)$ & 1 & 1 \\
\hline Dublin North $\ldots \ldots \ldots \ldots \ldots$ & 3 & 1 & 2 & & \\
\hline Dublin North-Central ... ... & 4 & 2 & $2(1)$ & & \\
\hline Dublin North-East ... . . . . & 4 & 2 & $2(1)$ & & \\
\hline Dublin North-West $\ldots \ldots \ldots$ & 4 & 2 & $1(2)$ & & $1 * *$ \\
\hline Dublin South $\ldots \ldots \ldots \ldots$ & 5 & 2 & 3 & & \\
\hline Dublin South-Central ... ... & 5 & 2 & $1(2)$ & $1(-)$ & 1 \\
\hline Dublin South-East $\ldots \ldots \ldots$ & 4 & $1(2)$ & 2 & $1(-)$ & \\
\hline Dublin South-West ... ... ... & 4 & 2 & 1 & 1 & \\
\hline Dublin West $\ldots \ldots \ldots \ldots$ & 5 & 2 & 3 & & \\
\hline $\begin{array}{lllll}\text { Dun Laoghaire } & \ldots & \ldots & \ldots & \ldots\end{array}$ & 5 & 2 & 2 & 1 & \\
\hline $\begin{array}{lllllll}\text { Galway East } & \ldots & \ldots & \ldots & \ldots & \ldots\end{array}$ & 3 & 2 & 1 & & \\
\hline Galway West $\ldots \ldots \ldots \ldots$ & 5 & 3 & 1 & 1 & \\
\hline $\begin{array}{lllllll}\text { Kerry North } & \ldots & \ldots & \ldots & \ldots & \ldots\end{array}$ & 3 & 2 & $-(-)$ & 1 & \\
\hline $\begin{array}{llllll}\text { Kerry South } & \ldots & \ldots & \ldots & \ldots & \ldots\end{array}$ & 3 & 1 & 1 & 1 & \\
\hline & $\begin{array}{l}5 \\
5\end{array}$ & $3(2)$ & $1(2)$ & & \\
\hline $\begin{array}{llllll}\text { Laois-Offaly } & \ldots & \ldots & \ldots & \ldots & \ldots \\
\text { Limerick East } & \ldots & \ldots & \ldots & \ldots\end{array}$ & $\begin{array}{l}5 \\
5\end{array}$ & $\begin{array}{l}3 \\
2\end{array}$ & $\begin{array}{l}2 \\
2\end{array}$ & & 1 \\
\hline $\begin{array}{llllll}\text { Limerick East } & \ldots & \ldots & \ldots & \ldots \\
\text { Limerick } & \text { West } & \ldots & \ldots & \ldots & \ldots\end{array}$ & $\begin{array}{l}5 \\
3\end{array}$ & $\begin{array}{l}2 \\
2\end{array}$ & $\begin{array}{l}2 \\
1\end{array}$ & & \\
\hline Longford-Westmeath $\ldots \quad \ldots$ & 4 & 2 & 2 & & \\
\hline Louth $\ldots \ldots \ldots \ldots \ldots \ldots$ & 4 & $3(2)$ & 1 & & \\
\hline $\begin{array}{lllllll}\text { Mayo East } & \ldots & \ldots & \ldots & \ldots & \ldots\end{array}$ & 3 & 2 & 1 & & \\
\hline $\begin{array}{llllll}\text { Mayo West } \ldots & \ldots & \ldots & \ldots & \ldots\end{array}$ & 3 & 2 & 1 & & \\
\hline Meath $\ldots \ldots \ldots \ldots \ldots$ & 5 & $3(2)$ & 2 & $-(1)$ & \\
\hline $\begin{array}{lllllll}\text { Roscommon } & \ldots & \ldots & \ldots & \ldots & \ldots\end{array}$ & 3 & 2 & 1 & & \\
\hline $\begin{array}{llllll}\text { Sligo-Leitrim } & \ldots & \ldots & \ldots & \ldots & \ldots\end{array}$ & 4 & $3(2)$ & $1(2)$ & & \\
\hline Tipperary North ... ... ....... & 3 & $1(2)$ & 1 & & \\
\hline Tipperary South $\ldots \ldots \ldots \ldots$ & 4 & 2 & 1 & 1 & \\
\hline $\begin{array}{llllll}\text { Waterford } & \ldots & \ldots & \ldots & \ldots & \ldots\end{array}$ & 4 & $1(2)$ & 2 & & $1 * *$ \\
\hline Wexford $\ldots \ldots \ldots c c c c$ & 5 & $3(2)$ & 2 & $-(1)$ & \\
\hline $\begin{array}{lllllll}\text { Wicklow } & \ldots & \ldots & \ldots & \ldots & \ldots & \ldots\end{array}$ & 4 & 1 & $2(1)$ & 1 & \\
\hline
\end{tabular}

* Los números entre paréntesis representan los escaños con los que contaba cada formación en la anterior legislatura.

** S. F.-W. P.

FUENTE: Embajada de la República de Irlanda. 
E1 Fianna Fail pierde un representante en las siguientes circunscripciones: Dublin South-East, Tipperary North y Waterford. Gana también uno en los siguientes: Cavan-Monagham, Kildare, Louth, Meath, Sligo-Leitrim y Wexford.

Para el Fine Gael el saldo es menos positivo; así, pierde cinco representantes, uno en cada una de las circunscripciones que siguen: Dublin Central, Dublin NorthWest, Dublin South-Central, Kildare y Sligo-Leitrim. Los dos únicos representantes que gana el Fine Gael provienen de Dublin North-Central y Dublin North-East. Quiero destacar la importancia que ha tenido para el Fine Gael -al menos en esta consulta electoral- el voto de los electores de Dublín con sus diez circunscripciones, pues de los cinco escaños perdidos, tres corresponden a otras tantas circunscripciones de la capital. En cuanto a los dos escaños conquistados, en el cuadro 2 se puede comprobar que proceden de los votos de otros dos distritos de Dublín. En cuanto al Labour Party, el resultado de estas elecciones no altera su presencia en el Dail.

Tras las elecciones, en una asamblea (pleno) del Dail celebrada el día 9 de marzo de 1982, fue elegido primer ministro el líder del partido Fianna Fail, Charles Haughey, quien ya ocupó el mismo cargo en la legislatura anterior a las elecciones de 1981 (antetiores a las que comento). El nuevo primer ministro fue elegido con los votos de su propio partido, además de los tres votos del S.F.W. P: y los de dos diputados independientes.

El sistema electoral irlandés, o de voto único transferible, es una combinación de la representación proporcional y el escrutinio mayoritario, de manera que los resultados respondan lo más fielmente a los deseos del elector. Para una mayor información sobre el sistema electoral irlandés, véanse E. Lakeman, How Democracies Vote, págs. 11 y sigs. (Faber and Faber, Londres, 1974); Jean Marie Cotteret y Claude Emeri, Les systèmes électoraux, págs. 78 a 80 (P.U.F., París, 1970).

Fernando Ollero Butler 